\title{
An inventory model for a three-stage supply chain with random capacities considering disruptions and supplier reliability
}

\author{
Md. Tariqul Islam ${ }^{1} \cdot$ Abdullahil Azeem $^{1} \cdot$ Masum Jabir $^{1} \cdot$ Ananna Paul $^{2}$. \\ Sanjoy Kumar Paul ${ }^{3}$ (D) \\ Published online: 15 May 2020 \\ (c) Springer Science+Business Media, LLC, part of Springer Nature 2020
}

\begin{abstract}
This study develops an inventory model to solve the problems of supply uncertainty in response to demand which follows a Poisson distribution. A positive aspect of this model is the consideration of random inventory, delivery capacities and supplier's reliability. Additionally, we assume supplier capacity follows an exponential distribution. This inventory model addresses the problem of a manufacturer having an imperfect production system with single supplier and single retailer and considers the quantity of product $(\mathrm{Q})$, reorder points $(\mathrm{r})$ and reliability factors (n) as the decision variables. The main contribution of our study is that we consider supplier may not be able to deliver the exact amount all the time a manufacturer needed. We also consider that the demand and the time interval between successive availability and unavailability of supplier and retailer follows a probability distribution. We use a genetic algorithm to find the optimal solution and compare the results with those obtained from simulated annealing algorithm. Findings reveal the optimal value of the decision variables to maximize the average profit in each cycle. Moreover, a sensitivity analysis was carried out to increase the understanding of the developed model. The methodology used in this study will help manufacturers to have a better understanding of the situation through the joint consideration of disruption of both the supplier and retailer integrated with random capacity and reliability.
\end{abstract}

Keywords Inventory model $\cdot$ Disruption $\cdot$ Supply chain $\cdot$ Supply uncertainty $\cdot$ Reliability

\section{Introduction and background of the study}

Currently, inventory is considered to be one of the more costly operating expenses of business. In some industries, inventory management has emerged as a critical factor in profitability and productivity optimization. A supply chain is a system that involves all the facilities or entities that are required to transform raw materials into final products. It consists of stages, like suppliers, manufacturers, distributors, wholesalers and retailers, etc. In practice, supply chains are highly uncertain. Supplier reliability, uncertainty and poor performance in one stage can affect the whole supply chain. These disruptions can occur on the supplier

Extended author information available on the last page of the article 
and retailer sides. To anticipate the disruption situations similar to real world scenarios, we considered two states (ON and OFF) to define the status of both the supplier and retailer. ON state indicates that the supplier is available for placing a new order \& OFF state means supplier is currently unavailable for that purpose. Disruptions that are beyond human control cannot be undone, but if proper measures are taken, reordering points, order quantities and optimum supplier reliability can be set in such a way so as to maximize the total gains of a replenishment cycle. A highly reliable supplier leads to a high-quality product which, in turn, reduces inspection and rejection costs, at the same time increasing purchasing cost. Therefore, supplier reliability should be set at a certain limit. To make the inventory model closer to a "real life" scenario, we included supplier reliability in our inventory model. Since inventory cost has become a key concern for organizations and managers, these groups are interested in reducing this cost most of the time. Hence, the objective of a company is to maximize their profit by considering some inventory cost parameters, so that this cost is the lowest possible at any particular period.

Operations research, computer science, production inventory systems and management have emerged as the most crucial research interests for many researchers and academics. In previous studies, many researchers concentrated on developing inventory models for ideal situations. For example, Parlar and Berkin (1991) established an inventory model where supply disruption was considered. Their main assumption was that the supplier's state is known to the decision maker, and they are in either an ON or OFF state. They also presumed that the decision maker follows a ZIO (Zero Inventory Ordering) standard where an order is placed when inventory levels reach zero. Parlar and Perry (1995) established another inventory model where the state of the supplier was unknown to the decision maker, like in their previous work. Again, ZIO policy was not followed. Rather there was a reorder point. Gupta (1996) assumed that customer demand follows a Poisson process and that lost sales are generally caused by shortages. He also considered a non-zero (but deterministic) lead time. Parlar (1997) focused on a review-type inventory problem which is continuous and stochastic in nature, considering random demand and random lead times, where the availability of the supplier was modelled as a semi-Markov process. In this case, the standard $(\mathrm{q}, \mathrm{r})$ policy was followed when the supplier was available (ON). Heydari and Norouzinasab (2016) developed a two-stage supply chain involving a single manufacturer and single retailer, where they proposed an incentive policy to fix pricing strategies, lead time and ordering. They assumed that stochastic demand is dependent on price and lead time. Yao and Minner (2017) presented an inventory model that includes different supply options (multiple-sourcing, transhipment, supplier selection methods) and summarized their influence from managerial perspective. Cárdenas-Barrón et al. (2018) proposed an inventory model by assuming that ending inventory level can be negative. Their work formulated an economic order quantity model to maximize the retailer's total profit per unit time under nonlinear holding cost and demand. Lücker et al. (2019) focused on managing disruption considering reserve capacity for inventory decisions and stochastic demand simultaneously. Moreover, they assumed zero lead time to neglect the effects of safetly stock in their mathematical model. Dem et al. (2019) worked on an inventory model where defective and non-defective items can be produced. In their study, they thought that demand depends on defective and non-defective factors. An objective of the study was to find the optimal production policy to maximize profit where the reliability of the system was considered exponentially decreasing as a function of time.

Mohebbi and Hao (2006) explored the problems involved in a continuous review inventory system with Compound Poisson demand, Erlang-distributed lead times, and lost sales due to random supply interruptions. Dada et al. (2007) solved a newsvendor related problem with multiple suppliers, where any given supplier was characterized as either perfectly reliable 
(a supplier delivering an identically equal quantity to the desired quantity) or unreliable (a supplier, with some probability, delivering a quantity strictly less than the quantity expected). Sting and Huchzermeier (2012) analysed dual sourcing decisions considering supply and demand uncertainty which are stochastically dependent on each other. Results were extended to the rather wide range classes of endogenous supply uncertainty formed by Dada et al. (2007). Hishamuddin et al. (2013) developed a recovery model for a two-stage supply chain system considering disruption that can happen due to transportation. In their model, the authors tried to optimize ordering and production quantities during the disruption recovery window with a cost minimization objective. Li et al. (2017) considered a single stage supply chain where demand is deterministic and disruptions can lead to production delay. Their paper developed a cost minimization model by comparing proactive and reactive strategies in case of disruption management. Schmitt et al (2017) used a dynamic ordering approach and found considerable performance improvement compared to adaptive approach to mitigate supply disruptions. In their model they did not consider randomness in disruption duration which can be one important aspect for real world supply chain. Giri and Sarker (2019) worked on a three-echelon supply chain model where they considered a raw material supplier, one manufacturer and one retailer. They considered the way both the raw material supplier and manufacturer can have issues of disruption in their production. The objective of the study was to determine the optimal lot size for both the supplier and manufacturer and to maximize total profit.

Production process reliability has been considered by many researchers, such as Bag et al. (2009), Sana (2010), Mohebbi and Hao (2008), Sarkar (2012) and Paul et al. (2014a, b, c, 2015a, b, 2019a, b). Mohebbi and Hao (2008) inferred that in a stochastic inventory system, an unreliable supplier with a single item varies randomly between two feasible states (i.e., availability and unavailability), following a dual state continuous time-homogeneous Markov chain. Bag et al. (2009) developed an inventory model with three types of cost: holding cost, set up cost and production cost, where flexibility, demand and reliability are considered as fuzzy random variables. Sana (2010) established a mathematical model that optimizes the production rate and product reliability to determine the maximum cumulated profit for an imperfect manufacturing process. Qi (2013) worked on an inventory model for a retailer with a single product and constant demand. This model was a continuous review inventory model where replenishment decisions were made based on reliability, and costs were presented by two different suppliers. Paul et al (2013) developed a production inventory system that considered disruption in the production process. Silbermayr and Minner (2014) developed a supply chain with one buyer where demand follows the Poisson process. The buyer can order from a set of suppliers with unreliable supply performance. Torkul et al. (2016) worked on a model to arrange the reorder point in a time based manner to eliminate safety stock. Huang et al. (2018) developed a two-level supply chain model considering an unreliable supplier's production system and a price-sensitive retailer's demand. In this model, it was considered that production lines may shift between "in control" to "out of control" states randomly. Rohaninejad et al. (2018) focused on a multi-echelon supply chain where the reliability of the facilities can be improved by investing. One major assumption of their model was that the integrated optimization approach among stages are more effective than individual optimization. However, in their model other significant relations were absent such as the cost of supplying demand from one stage which can be dependent on the planned level of reliability to other echelon of the network. Yan et al. (2019) established an inventory model to define the order strategies of a two-stage supply chain system. They considered both of the suppliers unreliable and might cause random disruptions. Optimal ordering policy, order quantity and expected profit were derived from this model. To make the model more realistic, 
their single period disruption model can be extended to address multiple period disruption situations.

We found in most of the literature that the assumed lead time was zero. This meant that when an order was placed, a shipment was received instantly, or after a random or fixed lead time. Yet, researchers have assumed a supplier is always available when needed. However, as the examples provided have shown, this is not always the case. The supplier may be in a state of disruption for many reasons. They can be unavailable for a random time at random times. Another assumption has been that the retailer is always available. The main function of a retailer is to store inventory to satisfy demand. When events like a natural disaster or political strikes occur, there is a possibility that retailing is disrupted. For example, an end product may be destroyed and not reach the hands of the consumer. Such events may hamper the production of the manufacturer. If the manufacturer cannot deliver its product to the retailer, then it may not go into further production. The disruption at the supplier will impede supply reaching the manufacturer. The disruption at the retailer hampers the production of the manufacturer, the end product that will be consumed by the consumer, and also the inventory level of the retailer. Finally, in most of the cases reported above, the reliability of the supplier was not considered. Highly reliable suppliers give high-quality products, which reduces inspection and rejection costs. To summarize, the aims of the study are:

i. To formulate a three stage inventory model for a manufacturer facing random demand at random times;

ii. To develop a mathematical framework considering a single supplier and single retailer with random capacity and demand;

iii. To incorporate reliability of the supplier;

iv. To model and optimize the final profit function for the manufacturer; and

v. To understand the relationship among different decision variables through a numerical example.

In summary, the study will assist a manufacturer to have a clear understanding of an optimal inventory plan in case of disruption in both supplier and retailers end by considering random capacity and supplier's reliability.

All the assumptions described in this section were treated individually in various literature, but in this research, all of these assumptions are treated simultaneously. Here, disruptions at both the retailer and supplier are considered to take the inventory model one step closer to a real-world scenario. Also, supplier reliability is related to the inventory model. So, to make the inventory model closer to a real-world model of practice, we include supplier reliability in our inventory model. The main contribution of this paper can be summarized as follows:

i. Establishment of an updated efficient heuristic for generating a revised production plan after disruption.

ii. Development of a mathematical model for a manufacturer facing random demand considering that the supplier can face disruptions and random capacity.

iii. Extension of the heuristic considering various disruptions on a real-time basis. The revised plans may or may not be affected by any new disruptions after previous ones, where their situation may be viewed as dependent and independent and these scenarios can be handled by the new extended heuristic.

iv. Consideration that the reliability of the supplier in model development and both the supplier and retailer can be disrupted at random times.

v. Optimization of the resulting final objective equation of the formulated model using a suitable nonlinear optimization technique to get the value of the decision variables, which are mainly state respective order quantities, reorder point and reliability. 
The remaining section of the paper is organized as follows: the context of the problem for conducting this research has been described in Sect. 2. Section 3 represents the formulation of the mathematical model for the stated problem. The solution methods and algorithm process is discussed in Sect. 4. Section 5 and 6 deal with results analysis, graphical findings and sensitivity analysis. Finally, conclusions, discussions and directions for conducting future research are summarized in Sect. 6.

\section{Problem description}

In this paper, we consider that the supplier can be disrupted at random times and can remain off for a random length of time. The retailer can also be disrupted at random times and can remain off for a random length of time. A manufacturer has one supplier from whom they get a supply of raw materials, parts or sub-assemblies, and one retailer who is involved in keeping stock of the products manufactured by the manufacturer and keeping direct contact with the consumers by selling those. The supplier can be in an ON/OFF state and so too, the retailer. Moreover, the supplier has a random capacity. They cannot always supply the exact amount of supply needed when they get an order. The manufacturer wants to consider all these facts and wants to develop an inventory model and an ordering policy which will minimize their average cost. The manufacturer could backorder if they are not capable of meeting current demand. The assumptions made about the situation are given below.

i. Defective and non-defective items will be identified and separated through $100 \%$ inspection.

ii. There is a pricing policy for defective and non-defective items where defective items are sold at a lower price.

iii. Selling price of non-defective items is a function of markup $\left(\mathrm{m}_{1}\right)$ of production cost (P). Such as $\mathrm{S} 1=\mathrm{m}_{1} \mathrm{P} ; \mathrm{m}_{1}>1$.

iv. Selling price of defective items is a function of markup $\left(\mathrm{m}_{2}\right)$ and production cost $(\mathrm{P})$ such that $\mathrm{S} 2=\mathrm{m}_{2} \mathrm{P}$; where, $0<\mathrm{m}_{2}<1$

v. Holding cost is a function of process reliability.

vi. The supplier and the retailer can be available and unavailable at random times and the manufacturer does not know the availability of them beforehand.

vii. Demand generates according to the Poisson process where the supplier and retailer's length of $\mathrm{ON}$ and $\mathrm{OFF}$ periods are exponential random variables.

viii. To place an order, the supplier and retailer both need to be in ON state.

ix. Supplier's capacity follows an exponential distribution.

x. Average length of supply disruption is much higher than order delivery lead time. For this reason, the lead time for order delivery is considered zero.

Figure 1 presents the different stages involved in our single supplier and single retailer model with different inventory levels and the status of both the supplier and retailer are provided. We considered cycle length as the time gap between two successive order placements. Disruption can occur at both supplier and retailer, but if the supplier is OFF for a long time, then this can cause backorder costs. After a certain disruption there comes a recovery plan for that specific case, order quantity and reorder point. Reliability of the supplier is given by the model as a revised plan. 


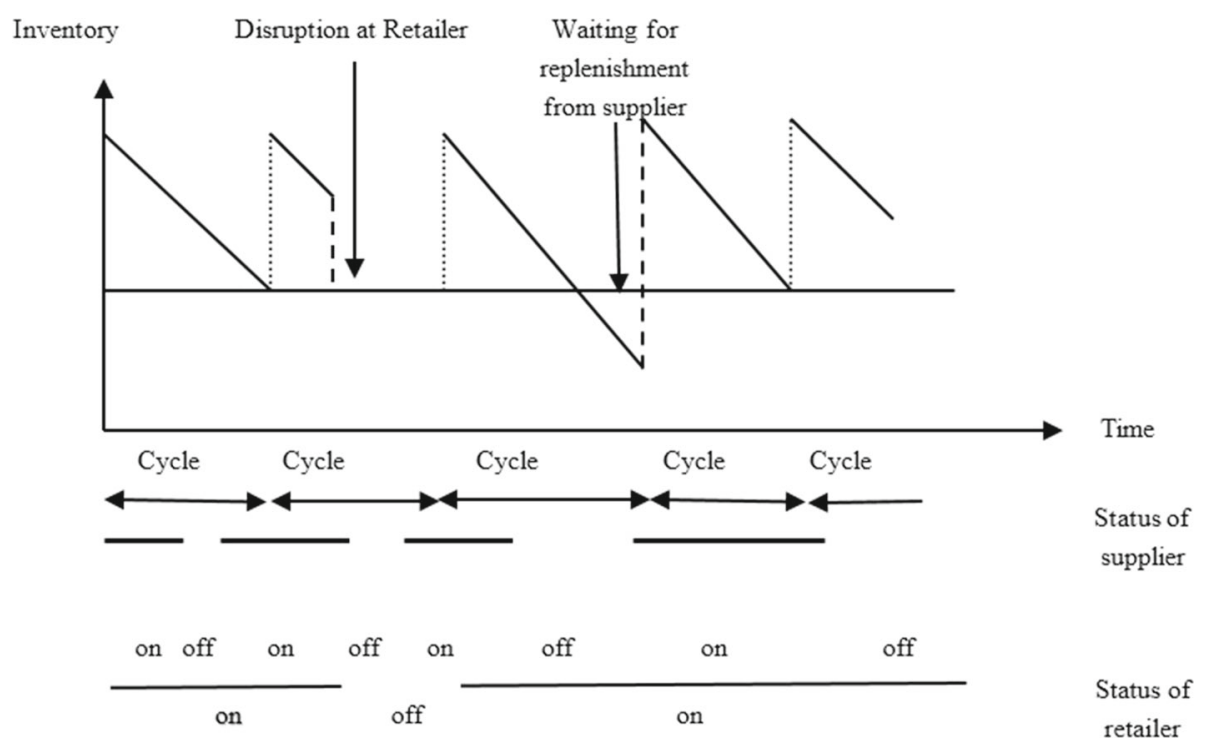

Fig. 1 Different states and inventory level status of one supplier and one retailer

Table 1 Probable states of the supplier and retailer

\begin{tabular}{lll}
\hline State & Supplier's status & Retailer's status \\
\hline 0 & ON & ON \\
1 & ON & OFF \\
2 & OFF & ON \\
3 & OFF & OFF \\
\hline
\end{tabular}

\section{Model formulation}

In this section, we develop a mathematical model for a single supplier, single retailer system. During this model development, we considered the supplier and retailer have random capacity and they can be available and unavailable at different times. The duration of the available period or ON state and the unavailable period or OFF state follows an exponential distribution. Supplier's length of ON period is denoted by a parameter $\lambda$ and OFF period is denoted by a parameter $\mu$. Similarly, retailer's duration of ON period is represented by a parameter $\alpha$ and OFF period is represented by a parameter $\beta$. There can be 4 different states for the supplier and the retailer depending on time. In Table 1 all these possible states are given (at $t=0$ the state must be 0 ).

In the model, we have 4 states depending upon the ON and OFF situation of the supplier and retailer. However, only in the state 0 can an order can be placed because both the supplier and the retailer are available at this time. The reorder quantity is $r$ for that state. On the other states $(1,2,3)$, the supplier or the retailer is in an OFF state, so there is no chance of supplying the product to the customer for those states. So, there is only one order quantity $\left(\mathrm{q}_{0}\right)$. The transient probabilities are defined as, $\mathrm{P}_{\mathrm{ij}}(\mathrm{t})=$ Probability \{ starting with state $\mathrm{i}$ at time 0 and finally at state $\mathrm{j}$ at time $\mathrm{t}\}$, here $\mathrm{i}, \mathrm{j}=0,1,2,3$. 
In summary, we can say that the manufacturer has a single supplier for replenishment and that the supplier can be unavailable at random periods of time. Similarly, the retailer can be unavailable at random times and cause supply disruption. When the state is 0 and the reorder point is reached, the manufacturer places orders for $q_{o}$ units. If the retailer or the supplier is unavailable at that ordering time, the manufacturer has to wait until they are available. After the reception of the order from the supplier, update inventory level will be $E\left(q_{i}\right)+r ; i=0$, 1,2 .

So, the average profit objective function is,

$$
A P\left(q_{o}, r, n\right)=\frac{C_{00}}{T_{00}}=\frac{E[\text { Profit per cycle }]}{E[\text { Length per cycle }]}
$$

\subsection{Notations used in the study}

In this paper, to formulate the mathematical model we used the notations below.

\begin{tabular}{|c|c|}
\hline$\lambda$ & ON period duration of the supplier \\
\hline$\mu$ & OFF period duration of the supplier \\
\hline$\alpha$ & ON period duration of the retailer \\
\hline$\beta$ & OFF period duration of the retailer \\
\hline$N$ & Process reliability as a decision variable \\
\hline$K$ & Ordering cost \\
\hline$H$ & Inventory holding cost/unit/time \\
\hline$\pi$ & Backorder cost/unit \\
\hline$\pi^{\prime}$ & Backorder cost/unit/time \\
\hline$\theta$ & Exponential distribution parameter of the supplier for their random capacity \\
\hline$Q$ & Supplier's ordering quantity \\
\hline$E(q)$ & Expected quantity received by the manufacturer from the supplier \\
\hline$R$ & Reorder point \\
\hline$\gamma$ & Average demand/unit/time \\
\hline$A P$ & Average profit \\
\hline$C_{00}$ & Total profit of a cycle \\
\hline$T_{00}$ & Time length of a cycle \\
\hline$P_{i j}(t)$ & Probability of going from initial state $\mathrm{i}$ to state $\mathrm{j}$ \\
\hline$P_{i}$ & Steady-state probability of state i \\
\hline$A_{i}$ & Total holding and ordering cost for state i \\
\hline$\Phi$ & Rate out of any state \\
\hline$P^{\prime}(t)$ & Kolmogorov differential equation corresponding to $P(t)$ \\
\hline$Q$ & Generator Matrix \\
\hline$U$ & Matrix consisting of the eigenvectors of matrix $Q$ \\
\hline$U^{-1}$ & Inverse of $U$ matrix \\
\hline$H$ & Diagonal Matrix \\
\hline$\omega$ & Eigenvalues of matrix $Q$ \\
\hline
\end{tabular}




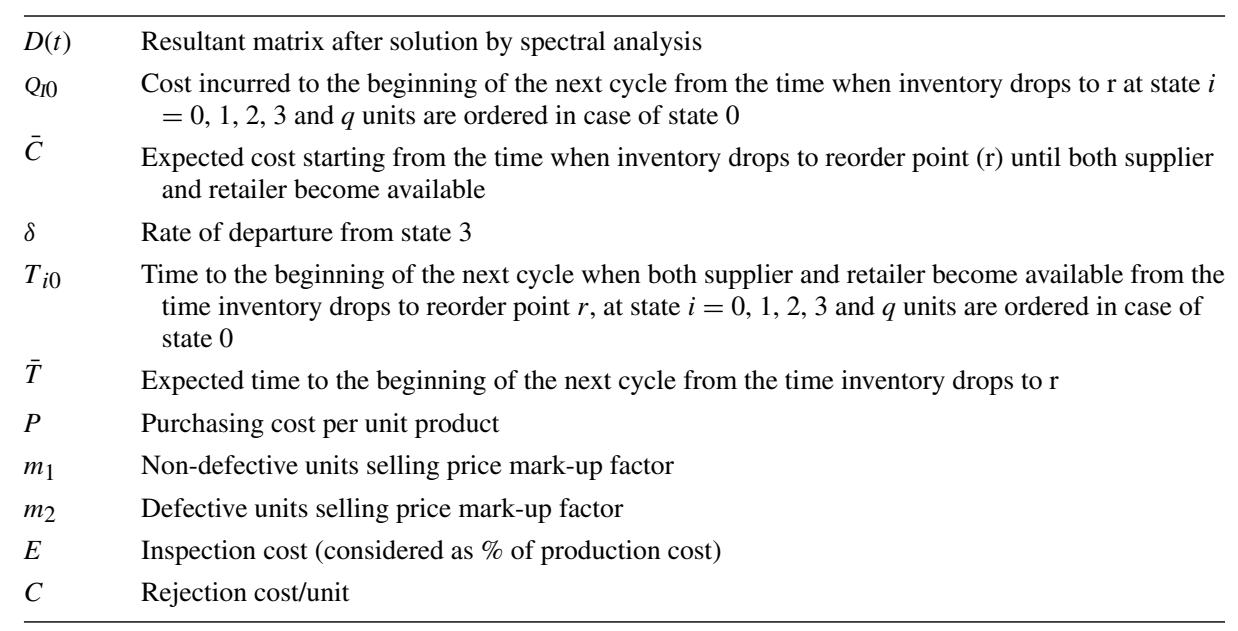

\subsection{Calculation of transient probabilities}

Let, $P(t)=\left[P_{i j}(t)\right], t \geq 0, i, j=0,1,2,3$ be the $4 \times 4$ transition functions matrix for the continuous time Markov chain. The problem is to find the exact transient solution of this matrix. There is a special way of deriving these transient probabilities which is known as Kolmogorov forward equations. This is a system of ordinary differential equations governing the behaviour of the probabilities $P_{i j}(t)$. The structure of the equation is as follows

$$
P_{i j}^{\prime}(t)=-\emptyset(j) P_{i j}(t)+\sum_{y \neq j} P_{i y}(t) \emptyset(y, j)
$$

Here y denotes some intermediate state between $\mathrm{i}$ and $\mathrm{j}$ and $\varphi$ stands for the rate out of any state. For example, $P^{\prime}{ }_{00}(t)$ and $P^{\prime}{ }_{01}(t)$ can be evaluated with the following equation:

$$
\begin{aligned}
& P_{00}^{\prime}(t)=-(\lambda+\alpha) P_{00}(t)+\beta P_{01}(t)+\mu P_{02}(t) \\
& P_{01}^{\prime}(t)=-(\lambda+\beta) P_{01}(t)+\alpha P_{00}(t)+\mu P_{02}(t)
\end{aligned}
$$

In the same way, other differential equations are also possible. However, we can put these 16 Kolmogorov equations in a more convenient matrix differential form, as below:

$$
P^{\prime}(t)=P(t) Q \quad \text { with } \quad P(0)=1
$$

Here,

$$
Q=\left[\begin{array}{cccc}
-(\lambda+\alpha) & a & \lambda & 00 \\
\beta & -(\lambda+\beta) & 0 & \lambda \\
\mu & 0 & -(\alpha+\mu) & \mu \\
0 & \mu & \beta & -(\mu+\beta)
\end{array}\right]
$$

where $\mathrm{Q}$ is the generator matrix of the Markov chain. $P(t)=\mathrm{e}^{Q t}$ is the solution of the above matrix differential equation and $\mathrm{e}^{Q t}$ is the matrix exponent, which is defined as:

$$
e^{Q t}=\sum_{n=0}^{\infty} \frac{t^{n} Q^{n}}{n !}
$$


Now, spectral theory is going to be used to define the values of $Q$.

$$
Q=U H U^{-1}
$$

where $U$ is the non-singular matrix formulated with the right eigenvectors of $Q$, and $H$ is the diagonal matrix. For the eigenvectors of $Q$, it is needed to find the eigenvalues of $Q$ at first, which is obtained as the solution of the characteristic equation,

$\operatorname{det}(Q-\omega I)=0$; solving gives

$$
\omega_{0}=0, \omega_{1}=-(\lambda+\mu), \omega_{2}=-(\alpha+\beta), \omega_{3}=-(\lambda+\mu+\alpha+\beta) ;
$$

Eigenvectors are decided using the abovementioned eigenvalues, and we get $U$ matrix as follows:

Inverse of the above matrix gives

$$
U=\left[\begin{array}{cccc}
1 & 1 & 1 & 1 \\
1 & 1 & -\beta / \alpha & -\beta / \alpha \\
1 & -\mu / \lambda & 1 & -\mu / \lambda \\
1 & -\mu / \lambda-\mu / \lambda & -\beta / \alpha & \mu \beta / \lambda \alpha
\end{array}\right]
$$

$$
\begin{gathered}
U^{-1}=U^{-1}=U^{-1}=\left[\begin{array}{cccc}
\mu \beta & \alpha \mu & \lambda \beta & \lambda \alpha \\
\lambda \beta & \alpha \mu & -\lambda \beta & -\lambda / \alpha \\
\alpha \mu & -\alpha \mu & \lambda \alpha & -/ \lambda \alpha \\
\lambda \alpha & -\lambda \alpha & -\lambda / \alpha & \lambda \alpha
\end{array}\right] \\
\text { If } Q=U H U^{-1} \text {, then } Q^{n}=\left(U H^{n} U^{-1}\right)
\end{gathered}
$$

Therefore, putting the value $\mathrm{Q}$, the final equation for the determination of transient probabilities are obtained as follows:

$$
P(t)=\sum_{n=0}^{\infty} \frac{\left(U H^{n} U^{-1}\right)}{n !}=U D(t) U^{-1}
$$

where,

$$
\begin{gathered}
D(t)=\left[\begin{array}{cccc}
1 & 0 & 0 & 0 \\
0 & e^{\omega_{1} t} & 0 & 0 \\
0 & 0 & e^{\omega_{2} t} & 0 \\
0 & 0 & 0 & e^{\omega_{3} t}
\end{array}\right]_{0} \\
D(t)=\left[\begin{array}{cccc}
1 & 0 & 0 & 0 \\
0 & e^{-(\lambda+\mu) t} & 0 & 0 \\
0 & 0 & e^{-(\alpha+\beta) t} & 0 \\
0 & 0 & 0 & e^{-(\lambda+\mu+\alpha+\beta) t}
\end{array}\right]
\end{gathered}
$$

Here, $(t)$ time is dependent on both distributions which are followed by the order quantity received and consumption. Received order quantity consumptions follow an Erlang Distribution. So, when both of the suppliers are available the order quantity $E\left(q_{0}\right)$, the $D_{11}$ can be found using the equations below:

$$
\begin{gathered}
D_{11}=\frac{Y}{E(q)} \int_{0}^{\infty}\left[e^{-(\lambda+\mu) x}\right](y x)^{E(q-1)} e^{-y x} d x \\
=\left(\frac{y}{y+\lambda+\mu}\right)^{E(q)}
\end{gathered}
$$

Similarly,

$$
D_{22}=\left(\frac{y}{y+\alpha+\beta}\right)^{E(q)}
$$


and

$$
D_{33}=\left(\frac{y}{y+\lambda+\mu+\alpha+\beta}\right)^{E(q)}
$$

To calculate the transition probability from state 0 to any other state $(1,2,3), D(t)$ can be used:

$$
D(t)=\left[\begin{array}{cccc}
-1 & 0 & 0 & 0 \\
0 & \left(\frac{\mathrm{y}}{\mathrm{y}+\lambda+\mu}\right) \mathrm{E}(\mathrm{q}) & 0 & 0 \\
0 & 0 & \left(\frac{\mathrm{y}}{\mathrm{y}+\alpha+\beta}\right) \mathrm{E}(\mathrm{q}) & 0 \\
0 & 0 & 0 & \left(\frac{\mathrm{y}}{\mathrm{y}+\lambda+\mu+\alpha+\beta}\right) \mathrm{E}(\mathrm{q})
\end{array}\right]
$$

So, with fixed values of $U$ and $U^{-1}$, transition probabilities will be generated from the below equations. The value of matrix $D(t)$ can be calculated from any of the three matrices defined above.

$$
P(t)=U D(t) U^{-1}
$$

The long-run probabilities $P_{j}=\lim _{t \rightarrow \infty} P_{i j}(t)$ are

$$
\left[P_{0} P_{1} P_{2} P_{3}\right]=\frac{1}{(\lambda+\mu)(\alpha+\beta)}[\mu \beta, \mu \alpha, \lambda \beta, \lambda \alpha]
$$

\subsection{Calculation of the cycle profit}

The cycle profit is comprised of six essentials. The selling price of non-defective units, selling price of defective units, holding cost, purchasing cost, ordering cost, inspection cost and rejection cost. When the state is 0 , new orders can be placed.

The total profit incurred per cycle $=$ (selling price of acceptable units $)+($ selling price of defected units $)-$ (ordering cost) - (holding cost - (inspection cost $)-$ (rejection cost)

Here,

$$
\begin{aligned}
& \text { Selling price of acceptable units }=P \times m 1 \times E(q) \\
& \text { Holding cost }=\frac{h E(q)}{\alpha} \times \frac{E(q)+r+r}{2} \\
& \text { Inspection cost }=P \times e \times \frac{E(q)}{n} \\
& \text { Purchasing cost }=P \times E(q) \times(1+n) \\
& \text { Rejection cost }=c \times E(q) \times\left(\frac{1-n}{n}\right) \\
& A[E(q), r, n]=A_{0}=P \times m 1 \times E(q)+P \times m 2 \times E(q) \times\left(\frac{1-n}{n}\right) \\
& -P \times E(q) \times(1+n)-k-\frac{h E(q)}{\alpha} \times \frac{E(q)+r+r}{2} \\
& -P \times e \times \frac{E(q)}{n}-c \times E(q) \times\left(\frac{1-n}{n}\right) \\
& =P \times m 1 \times E(q)+P \times m 2 \times E(q) \times\left(\frac{1-n}{n}\right)
\end{aligned}
$$




$$
\begin{aligned}
& -P \times E(q) \times(1+n)-k-\frac{h E\left(q^{2}\right)}{2 \alpha}-\frac{h E(q) r}{\alpha} \\
& -P \times e \times \frac{E(q)}{n}-c \times E(q) \times\left(\frac{1-n}{n}\right) \\
& \text { where } E(q)=\frac{1}{\theta} \times\left(1-e^{-\theta q}\right) \\
& \text { and } E\left(q^{2}\right)=\frac{2}{\theta^{2}}\left\{1-(1+\theta q) e^{-\theta q}\right\}
\end{aligned}
$$

Here, $C_{i o}=E$ [total profit until the start of the next cycle from the time when inventory is $\mathrm{r}$ at state $i=0,1,2,3$ and $q$ units order is placed at state 0 ]

Then,

$$
C_{i o}=P_{i o}\left(E\left(q_{i}\right)\right) A P\left(E\left(q_{i}\right), r, n\right)+\sum_{j=1}^{3} P_{i j}\left(E\left(q_{i}\right)\right)\left[A P\left(E\left(q_{i}\right), r, n\right)+C_{j o}\right] ; \quad i=0,1,2
$$

The transition profit involved to transfer from state $i$ to state 0 is defined by $C_{i 0}$. But it is not certain that state 0 will be reached on the first step. In between state $i$ and state 0 other states $\left(C_{10}, C_{20}, C_{30}\right)$ can be reached.

$$
C_{o o}=P_{o o}(E(q)) A P(E(q), r, n)+\sum_{j=1}^{3} P_{o j}\left(E\left(q_{i}\right)\right)\left[A P\left(E\left(q_{i}\right), r, n\right)+C_{j o}\right]
$$

This equation means when the supplier receives $E(q)$ amount, the total inventory level will increase $E(q)+r$. When $E(q)$ is consumed by the retailer, the manufacturer will return in other states like $0,1,2,3$, with probabilities $P_{00}(E(q)), P_{01}(E(q)), P_{02}(E(q)), P_{03}(E(q))$.

Therefore, we find,

$$
\begin{aligned}
& C_{00}=P_{00} A_{0}+P_{01} C_{10}+P_{02} C_{20}+P_{03} C_{30} \\
& C_{10}=P_{10} \bar{C}_{10}+P_{11} C_{10}+P_{12} C_{20}+P_{13} C_{30} \\
& C_{20}=P_{20} \bar{C}_{20}+P_{21} C_{10}+P_{22} C_{20}+P_{23} C_{30}
\end{aligned}
$$

However, $C_{30}$ formulation is different.

$$
\begin{aligned}
C_{30} & =\left(\bar{C}+C_{10}\right) r_{1}+\left(\bar{C}+C_{20}\right) r_{2} \\
& =\bar{C}+C_{10} r_{1}+C_{20} r_{2}
\end{aligned}
$$

where

$$
\rho_{1}=\frac{\mu}{\mu+\beta} \text { and } \rho_{2}=\frac{\beta}{\mu+\beta}
$$

Here, $\bar{C}$ is the expected profit which assumes the time duration from inventory status is $\mathrm{r}$ until the supplier or retailer become available again and its calculation method is the same as $\mathrm{C}_{10}$ is computed.

$$
\begin{aligned}
\bar{C} & =\int_{0}^{r / y} h y\left(\frac{r+r-\alpha y}{2}\right) \delta e^{\delta y} d y+\int_{r / y}^{\infty}\left\{\frac{h r^{2}}{2 \alpha}+\pi(y \alpha-r)+\pi^{\prime}\left(\frac{y^{2} \alpha}{2}+\frac{3 r^{2}}{2 \alpha}-2 y r\right)\right\} \delta e^{-\delta y} d y \\
& =e^{\delta r / \alpha}\left[-\frac{\pi^{\prime} r}{\delta}+\frac{h \alpha}{\delta^{2}}+\frac{\pi \alpha}{\delta}+\frac{\pi^{\prime} \alpha}{\delta^{2}}\right]+\frac{h r}{\delta}-\frac{h \alpha}{\delta^{2}}
\end{aligned}
$$


where $\delta=\mu+\beta$ is the rate of withdrawal from status 3. When the manufacturer reaches reorder point $\mathrm{r}$ and finds them in status 3 is equal to $C_{10}$. If it reaches state 1 then total profit will be $\bar{C}+C_{10}$ state 2 will cost $\bar{C}+C_{20}$. The probability of a transition from state 3 to 1 is:

$$
\begin{aligned}
P\left(Y_{1}<Y_{2}\right) & =\int_{0}^{\infty} P\left(Y_{1}<Y_{2} \text { given } Y_{2}=t\right) \beta e^{-\beta t} d t \\
& =\frac{\mu}{\mu+\beta}
\end{aligned}
$$

Rearranging the profit equations, we get,

$$
\left[\begin{array}{cccc}
P_{00} & -P_{01} & -P_{02} & -P_{03} \\
0 & 1-P_{11} & -P_{12} & -P_{13} \\
0 & -P_{21} & 1-P_{22} & -P_{23} \\
0 & -\rho_{1} & -\rho_{2} & 1
\end{array}\right]\left[\begin{array}{c}
C_{00} \\
C_{10} \\
C_{20} \\
C_{30}
\end{array}\right]=\left[\begin{array}{r}
A_{0} \\
P_{10} C_{10} \\
P_{20} C_{20} \\
\bar{C}
\end{array}\right]
$$

where

$$
\begin{aligned}
\bar{C}_{10}= & h y\left(\frac{r+r-\gamma y}{2}\right) ;[y y \leq r] \\
= & \frac{h r^{2}}{2 \gamma}+\pi(y \gamma-r)+\pi^{\prime} \int_{0}^{y-r / \gamma}(y \gamma-r) d y ;[y y \geq r] \\
& =\frac{h r^{2}}{2 \gamma}+\pi(y \gamma-r)+\pi^{\prime}\left(\frac{y^{2} \gamma}{2}+\frac{3 r^{2}}{2 \gamma}-2 y r\right) \\
\bar{C}_{10}(r)= & \int_{0}^{r / \gamma} h y\left(\frac{r+r-\gamma y}{2}\right) \mu e^{-\mu y} d y \\
+ & \int_{r / \gamma}^{\infty}\left\{\frac{h r^{2}}{2 \gamma}+\pi(y \gamma-r)+\pi^{\prime}\left(\frac{y^{2} \gamma}{2}+\frac{3 r^{2}}{2 \gamma}-2 y r\right)\right\} \mu e^{-\mu y} d y \\
= & e^{-\mu r / \gamma}\left[\frac{\pi^{\prime} r}{\mu}+\frac{h \gamma}{\mu 2}+\frac{\pi \gamma}{\mu}+\frac{\pi^{\prime} \gamma}{\mu^{2}}\right]+\frac{h r}{\mu}-\frac{h \gamma}{\mu^{2}}
\end{aligned}
$$

Similarly,

$$
\begin{gathered}
\bar{C}_{20}=r y \gamma+\pi^{\prime} \int_{0}^{y} y \gamma d y \\
=\pi y \gamma+\pi^{\prime} \gamma \frac{y^{2}}{2} \\
\bar{C}_{20}(r)=\int_{0}^{\infty}\left[\pi y \gamma+r^{\prime} \gamma \frac{y^{2}}{2}\right] \beta \mathrm{e}^{\beta \mathrm{y}} d y \\
=\frac{r \gamma}{\beta}+\frac{\pi^{\prime} \gamma}{\beta^{2}}
\end{gathered}
$$

Now,

$$
\begin{aligned}
& C_{10}\left(1-P_{11}\right)-P_{12} C_{20}-P_{13} C_{30}=P_{10} \bar{C}_{10} \\
& \text { Or, } C_{10}\left(1-P_{11}\right)-P_{12} C_{20}-P_{13}\left(\bar{C}+C_{10} \rho_{1}+C_{20} \rho_{2}\right)=P_{10} \bar{C}_{10} \\
& \text { Or, } \quad C_{10}\left(1-P_{11}-P_{13} \rho_{1}\right)-C_{20}\left(P_{12}+P_{13} \rho_{2}\right)=P_{10} \bar{C}_{10}+P_{13} \bar{C}
\end{aligned}
$$

Again,

$$
-C_{10} P_{21}+C_{20}\left(1-P_{22}\right)-P_{23} C_{30}=P_{20} \bar{C}_{20}
$$




$$
\begin{aligned}
& \text { Or, }-C_{10} P_{21}+C_{20}\left(1-P_{22}\right)-P_{23}\left(\bar{C}+C_{10} \rho_{1}+C_{20} \rho_{2}\right)=P_{20} \bar{C}_{20} \\
& \text { Or, }-C_{10}\left(P_{21}+P_{23} \rho_{1}\right)+C_{20}\left(1-P_{22}+P_{23} \rho_{2}\right)=P_{20} \bar{C}_{20}+P_{23} \bar{C}
\end{aligned}
$$

Hence, we get,

$$
\left[\begin{array}{cc}
\left(1 P_{11}-P_{13} \rho_{1}\right. & -\left(P_{12}+\mathrm{P}_{13} \rho_{2}\right) \\
-\left(P_{21}+P_{23} \rho_{1}\right) & \left(1-P_{22}+P_{23} \rho_{2}\right)
\end{array}\right]\left[\begin{array}{l}
\sigma_{1} \\
\sigma_{2}
\end{array}\right]=\left[\begin{array}{c}
P_{10} \bar{C}_{10}+P_{13} \bar{C} \\
P_{20} \bar{C}_{20}+P_{23} \bar{C}
\end{array}\right]
$$

where, $\left[\sigma_{1} \sigma_{2}\right]^{\prime}=\left[\begin{array}{lll}C_{10} & \mathrm{C}_{20}\end{array}\right]^{\prime}$ solves the system

Therefore,

$$
C_{00}=A_{0}+P_{01} \sigma_{1}+P_{02} \sigma_{2}+P_{03}\left(\bar{C}+\rho_{1} \sigma_{1}+\rho_{2} \sigma_{2}\right)
$$

\subsection{Calculation of the cycle length}

The final average profit objective has two components, one of which (cost benefit of the cycle $\left.C_{00}\right)$ is already defined. So, the remaining length of the cycle is $\left(T_{00}\right)$. Now, let us define $T_{i 0}$ $=E$ [time to the start of the next cycle from the time when the inventory level is $r$ at state $i$ $=0,1,2,3$ and $q$ units order is placed when state is 0$]$.

Then,

$$
T_{i 0}=P_{i 0}\left(E\left(q_{i}\right)\right) \frac{E\left(q_{i}\right)}{\gamma}+\sum_{j=1}^{3} P_{i j}\left(E\left(q_{i}\right)\right)\left[E\left(q_{i}\right) / \gamma+T_{j o}\right] ; i=0,1,2
$$

Here we have $T_{10}, T_{20}, T_{30}$. Using the equations above, cycle length $T_{00}$ can be described as:

$$
T_{00}=P_{00}\left(E\left(q_{0}\right)\right) \frac{E\left(q_{i 0}\right)}{\gamma}+\sum_{j=1}^{3} P_{0 j}\left(E\left(q_{0}\right)\right)\left[E\left(q_{0}\right) / \gamma+T_{j o}\right]
$$

This equation means when the $E(q)$ amount is received by the manufacturer, the inventory level will reach $E(q)+r$. After finishing $E(q)$ the manufacturer will be in state $0,1,2,3$ with probabilities of $P_{00}(E(q)), P_{01}(E(q)), P_{02}(E(q)), P_{03}(E(q))$.

The equations of $T_{10}$ and $T_{20}$ can be derived similarly.

Thus,

$$
T_{00}=P_{00} \frac{E(q)}{\gamma}+P_{01}\left\{\frac{E(q)}{\gamma}+T_{10}\right\}+P_{02}\left\{\frac{E(q)}{\gamma}+T_{20}\right\}+P_{03}\left\{\frac{E(q)}{\gamma}+T_{30}\right\}
$$

Therefore,

$$
\begin{aligned}
T_{00} & =\frac{E(q)}{\gamma}+P_{01} T_{10}+P_{02} T_{20}+P_{03} T_{30} \\
T_{10} & =P_{10} \bar{T}_{10}+P_{11} T_{10}+P_{12} T_{20}+P_{13} T_{30} \\
T_{20} & =P_{20} \bar{T}_{20}+P_{21} T_{10}+P_{22} T_{20}+P_{23} T_{30} \\
T_{30} & =\bar{T}+\frac{\mu}{\delta} T_{10}+\frac{\beta}{\delta} T_{20} \\
& =\bar{T}+\rho_{1} T_{10}+\rho_{2} T_{20}
\end{aligned}
$$

Here $\bar{T}=\frac{\mu}{\mu+\beta}$. 
At state 3, depending on the distribution of the disruption duration, it can be in state 1 or 2 in the next step. If it goes back to state 1 then the total time will be $\bar{T}+T_{10}$ and if it goes back to state 2 , the total time will be $\bar{T}+T_{20}$. The probability of state 3 to 1 transition is the same cycle cost calculation, which is given below:

$$
P\left(Y_{1}<Y_{2}\right)=\frac{\mu}{\mu+\beta}
$$

Rearranging equations (v), (vi), (vii) and (viii) we get,

$$
\left[\begin{array}{cccc}
1 & -\mathrm{P}_{01} & -\mathrm{P}_{02} & -\mathrm{P}_{03} \\
0 & 1-\mathrm{P}_{11} & -\mathrm{P}_{12} & -\mathrm{P}_{13} \\
0 & -\mathrm{P}_{21} & 1-\mathrm{P}_{22} & -\mathrm{P}_{23} \\
0 & \rho_{1} & \rho_{2} & 1
\end{array}\right]\left[\begin{array}{c}
\mathrm{T}_{00} \\
\mathrm{~T}_{10} \\
\mathrm{~T}_{20} \\
\mathrm{~T}_{30}
\end{array}\right]=\left[\begin{array}{r}
\frac{E(q)}{\gamma} \\
P_{10} \bar{T}_{10} \\
P_{20} \bar{T}_{20} \\
\bar{T}
\end{array}\right]
$$

Here,

$$
\begin{gathered}
\bar{T}_{10}=\frac{P_{10}}{\mu}+P_{13}\left[\frac{1}{\mu}+T_{30}\right] \\
\bar{T}_{20}=\frac{P_{20}}{\beta}+P_{23}\left[\frac{1}{\beta}+T_{30}\right] \\
\text { where } \delta=\mu+\beta
\end{gathered}
$$

From the matrix we get,

$$
T_{10}\left(1-P_{11}-P_{13} \rho_{1}\right)-T_{20}\left(P_{12}+P_{13} \rho_{2}\right)=P_{10} \bar{T}_{10}+P_{13} \bar{T}
$$

and,

$$
T_{10}\left(P_{21}-P_{23} \rho_{1}\right)+T_{20}\left(1-P_{22}+P_{23} \rho_{2}\right)=P_{20} \bar{T}_{20}+P_{23} \bar{T}
$$

From Eqs. (48) and (49) we get,

$$
\left[\begin{array}{cc}
\left(1-P_{11}-P_{13} \rho_{1}\right) & -\left(\mathrm{P}_{12}+\mathrm{P}_{13} \rho_{2}\right) \\
-\left(\mathrm{P}_{21}+\mathrm{P}_{23} \rho_{1}\right) & \left(1-\mathrm{P}_{22}+\mathrm{P}_{23} \rho_{2}\right)
\end{array}\right]\left[\begin{array}{l}
\psi_{1} \\
\psi_{2}
\end{array}\right]=\left[\begin{array}{c}
P_{10} \bar{T}_{10}+P_{13} \bar{T} \\
P_{20} \bar{T}_{20}+P_{23} \bar{T}
\end{array}\right]
$$

where $\left[\psi_{1} \psi_{2}\right]^{\prime}=\left[T_{10} T_{20}\right]^{\prime}$ solves the system.

Therefore, as total profit per cycle $\mathrm{C}_{00}$, and length of the cycle $\mathrm{T}_{00}$ is defined, the average profit objective function now can be written as:

$$
A P(q, r, n)=\frac{C_{00}}{T_{00}}=\frac{A_{0}+P_{01} \sigma+P_{02} \sigma_{2}+P_{03}\left(\bar{C}+\rho_{1} \sigma_{1}+\rho_{2} \sigma_{2}\right)}{\frac{E(q)}{\gamma}+P_{01} \psi_{1}+P_{02} \psi_{2}+P_{03}\left(\bar{T}+\psi_{1} \rho_{1}+\rho_{2} \psi_{2}\right)}
$$

The objective is to maximize the above equation and to get the optimum values of the decision variables. The ordering policy can be determined using the profit function. The maximization of this profit function will give the desired reliability, order quantity, and reorder point that are desired by the supplier.

\section{Solution approach}

In this research, we have formulated a mathematical model that considers a production inventory system under Poisson demand with supplier and retailer uncertainty, random supplier 
capacity and supplier reliability. Here, the reliability of the supplier, quantity ordered and re-order points are considered as decision variables for this model. The market demand, revenue, inventory holding cost, set-up cost, inspection cost, rejection cost and the reliability of the supplier are also considered. This model denotes a geometric programming model that has been solved through the use of simple methodology.

The example presented in this paper is quite similar to the case used in Parlar and Perry (1995). However, the model presented here is an improved version of their model and some new parameters have been introduced. A manufacturer maintains a supplier and their capacity is exponentially distributed considering a parameter $(\theta)$ that has a value of 0.025 . The manufacturer uses a retailer to sell products, where the retailer can get disrupted. Moreover, the availability or unavailability of the retailer and the supplier is unknown to the manufacturer. Due to these factors, the manager often finds it difficult to meet the demands of the customers in time. As a result, in recent years, they have tried to sort out this problem and develop a special ordering strategy to recover from their current status. Sometimes, a fraction of the produced items are defective. However, the amount of the fraction depends on the operating conditions. Generally, the reliability and fraction of defects have an inverse relationship. This means the higher the reliability, the lower the percentage of defects which, in turn, leads to higher operating costs. Additionally, the defective units can be sold at a low price. So, it is of crucial importance to determine the level of reliability that will maximize total profit for the organization.

From the historical data, with the help of a statistical goodness of fit test, it was found that supplier's and retailer's length of available/ON and unavailable/OFF cycles are considered as exponentially distributed. In the case of the supplier, the value of the parameters representing the length of the ON period was 0.25 and the length of the OFF period was 2.5. Whereas, in the case of the retailer, the value of the parameters denoting the length of the ON period was 1 and the length of the OFF period was 0.6. For the supplier, the ordering cost (k) was $\$ 10 /$ order. The demand for the quantity received from the supplier was determined through a Poisson process that considered an average rate of demand as 5 units.

Here, we have considered a modified $(\mathrm{Q}, \mathrm{r}, \mathrm{n})$ policy which is developed in this paper for one retailer and one supplier. Our research considers the optimal values of the decision variables that will maximize the total average profit. Table 2 below summarizes the values for the input parameters used in this model.

\section{Experimental results and analysis}

For the hypothetical problem described in the previous section, the proposed model is optimized so that the required three decision variables, i.e. the order quantity from the supplier (q) the reordering quantity (r) and reliability (n), can be determined. For this purpose, we have solved the problem with Genetic Algorithm (GA) and Simulated Annealing (SA) Algorithm and compared the results to understand the quality of the solutions. MATLAB R2016b was used to formulate the computer programming code for the problem.

GA was used to get the optimum values of the decision variables that maximize the average profit per cycle. Through the use of GA, we determined three findings that are shown in Table 3.

GA parameters used: Population type: Double vector

Creation function: Constraint dependent

Population size: 50 
Table 2 Parameter values used

\begin{tabular}{lc}
\hline Parameter & Values \\
\hline$P$ & 20 \\
$m_{1}$ & 3 \\
$m_{2}$ & 0.2 \\
$\varepsilon$ & 0.05 \\
$C$ & 5 \\
$H$ & 2 \\
$K$ & 50 \\
$\Pi$ & 25 \\
$\pi^{\prime}$ & 2.5 \\
$\lambda$ & 0.25 \\
$\mu$ & 2.5 \\
$\alpha$ & 1 \\
$\beta$ & 0.6 \\
$\theta$ & 0.025 \\
$\gamma$ & 5 \\
\hline
\end{tabular}

Table 3 Comparison of results obtained from GA and SA approaches

\begin{tabular}{lllll}
\hline Solution approach & Order quantity $(\mathrm{q})$ & Reorder point (r) & Reliability (n) & Maximum profit \\
\hline Genetic algorithm & 16.669 & 3.077 & 0.563 & 18.0165 \\
Simulated annealing & 15.842 & 3.048 & 0.556 & 18.0028 \\
\hline
\end{tabular}

Function tolerance: $1 \mathrm{e}-6$

Constraint tolerance: $1 \mathrm{e}-6$

Crossover function: 0.8

Lower bounds: Order quantity $=0$, reorder point $=0$, reliability $=0$

Upper bound: Order quantity $=1000$, reorder point $=100$, reliability $=1$

From 30 different runs using GA solver, we attained average fitness value (average cycle profit) 17.7474 units with a standard deviation of 1.303. Among 30 runs, maximum cycle profit obtained was 18.0165 units with order quantity 16.669 units, reorder point 3.077 units and reliability 0.563 units. Fintess value for run 17 is shown in Fig. 2.

SA parameters used:

Max iteration: infinity

Annealing function: fast annealing

Temperature update function: exponential temperature update

Initial temperature: 100

Start point: Order quantity $=100$, reorder point $=50$, reliability $=0.5$

Lower bounds: Order quantity $=0$, reorder point $=0$, reliability $=0$

Upper bound: Order quantity $=1000$, reorder point $=100$, reliability $=1$

Similarly we run the SA solver 30 different times and finally attained average fitness value (average cycle profit) 17.6855 units with a standard deviation of 0.38 . Among 30 runs, maximum cycle profit obtained was 18.0028 units with order quantity 15.842 units, reorder point 3.048 units and reliability 0.556 units. Fintess value for run 9 is shown in Fig. 3. We 


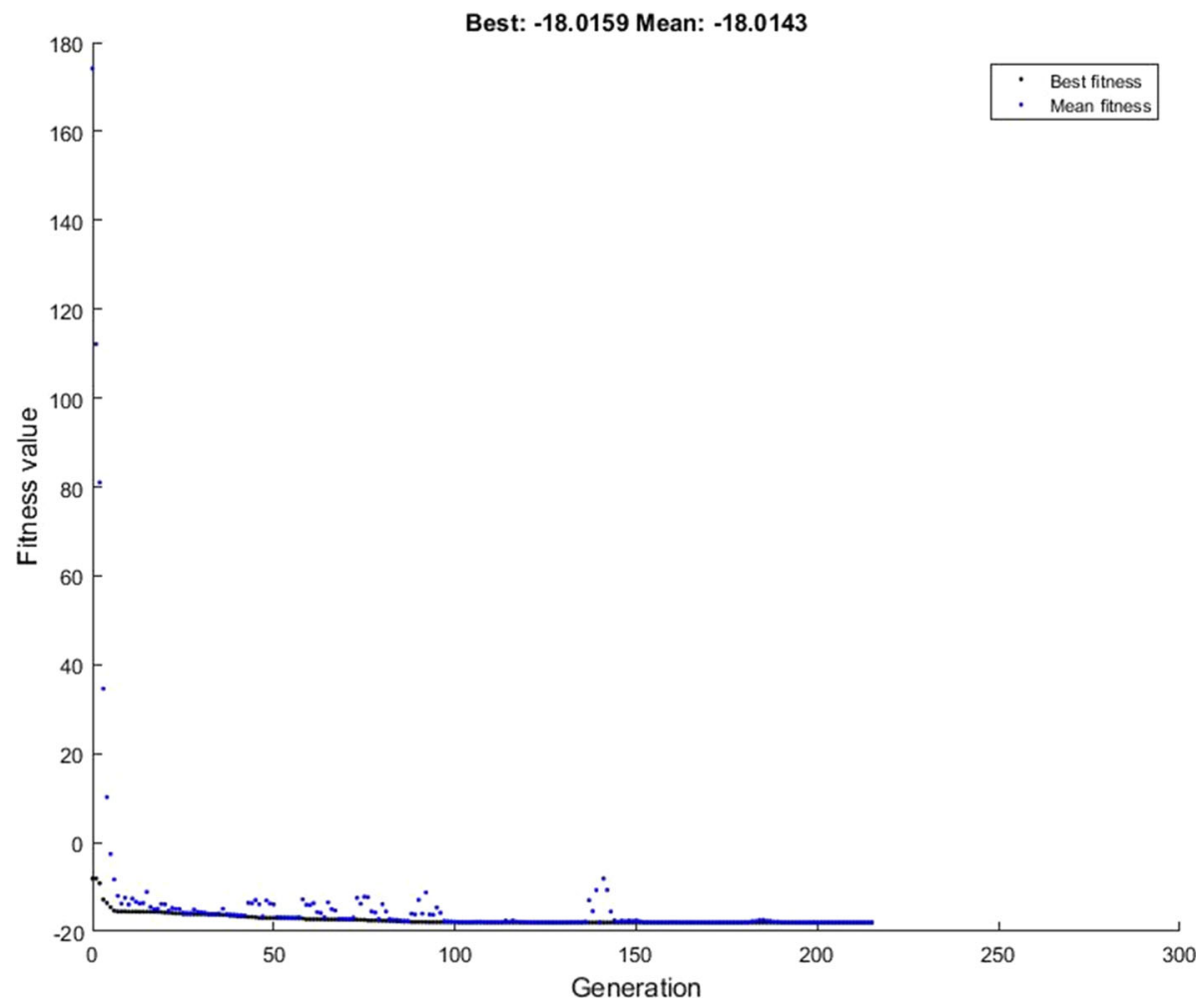

Fig. 2 GA fitness value versus generation for Run 17

have summarized the results obtained from GA and SA and presented in Table 3. From the comparison, it's evident that the results from GA and SA are quite close.

To observe the effect of three decision variables on the total profit, we plotted each independent variable on the $\mathrm{X}$-axis, keeping all other variables constant, and the resulting values of average profit are plotted on the Y-axis. Again, we plotted all the other parameter values against the decision variables separately. These graphs are presented in Figs. 4, 5 and 6.

Figure 4 (see Table 6 in Appendix) shows the relation between average profit and reliability. As reliability increases, average profit increases. Initially, at a very low reliability, profit is negative because of higher holdings, inspection and rejection costs. By increasing the reliability, we can see that average profit increases but after a certain point, this reaches a saturation point, where if we increase reliability this would reduce the benefit and increase other costs, such as purchasing costs from the supplier due to a more reliable supply. This maximization of profit falls in the range of 0.6-0.7 in our model. So, after this, increasing reliability will nothing but reduce average profit.

Figure 5 (see Table 7 in Appendix) shows the relationship between average profit and quantity ordered. When the quantity being ordered is increased, the ordering cost decreases. At the same time, holding costs increase. As the ordering cost is much larger than the holding cost at this point in general, i.e. the average cost decreases. Beyond this, the holding cost becomes too high and the reduced ordering cost can no longer mitigate the increased holding cost. So, the average cost again starts to increase. It also satisfies the classic EOQ model. 


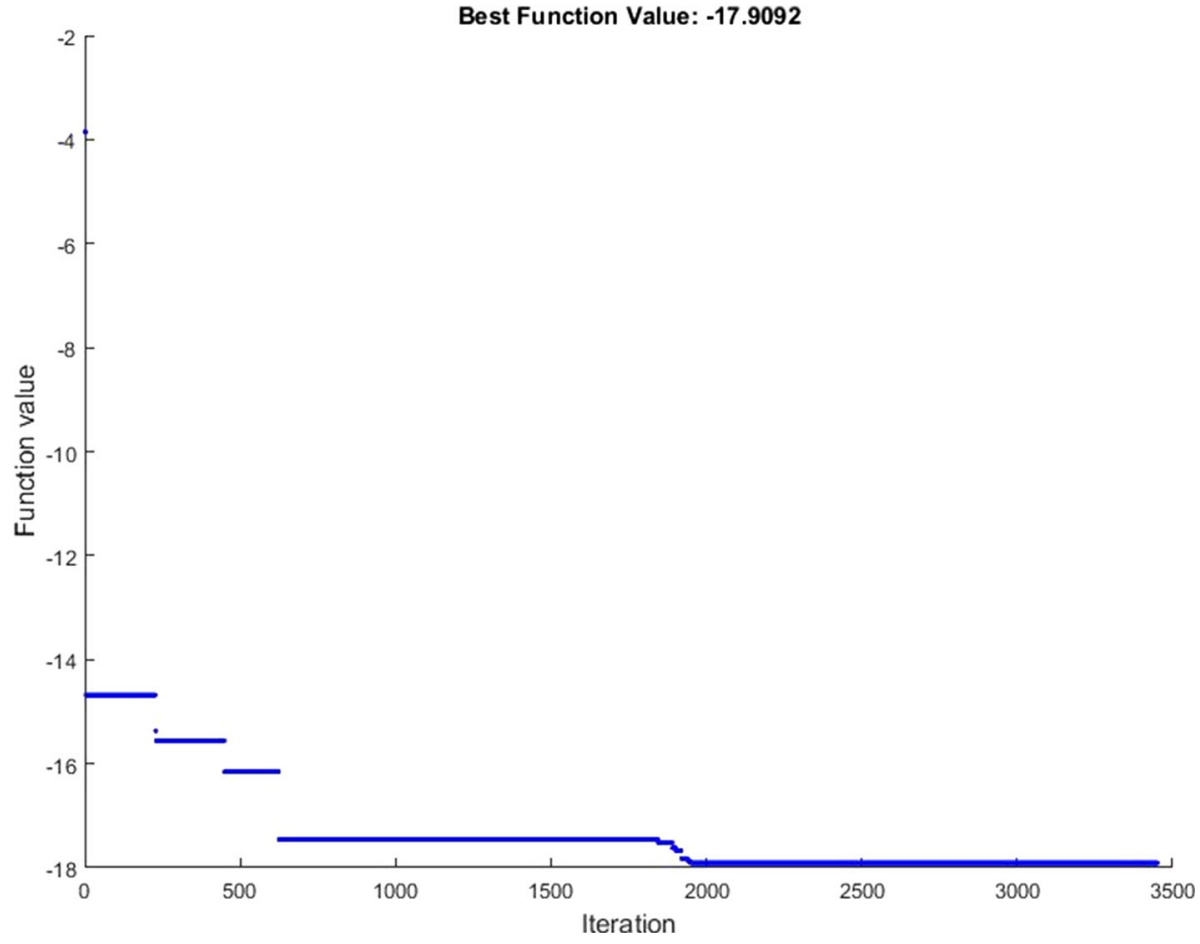

Fig. 3 SA function value versus iteration for Run 9

Profit vs reliability

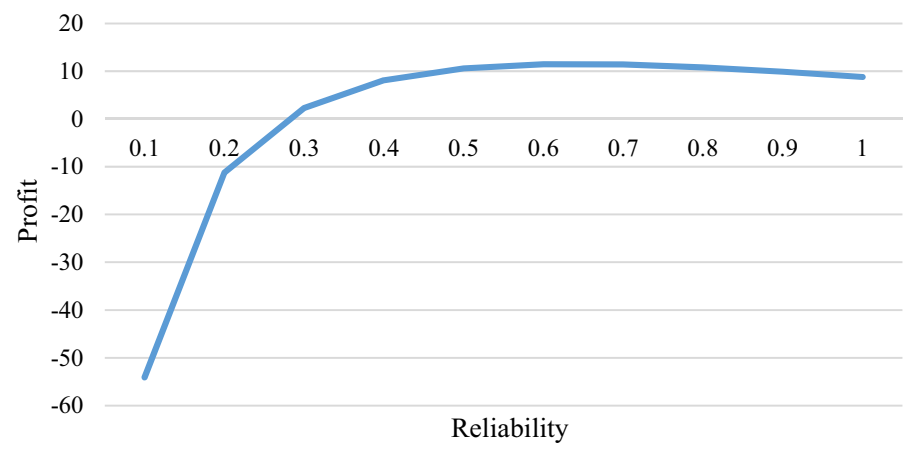

Fig. 4 Average profit versus reliability

Figure 6 (see Table 8 in Appendix) shows the relationship between average profit vs reordering point. As the reordering point is increased, the probability of shortage and backlog decreases drastically, as does the cost amount associated with it. So, the average cost decreases at first. Again, after reaching the optimum quantity, the reordering point is increased further, the safety stock in the inventory faces a crisis. Due to excessive safety stock, the holding cost increases rapidly. As a result, further increases in the reordering quantity cause the average cost to increase again. 


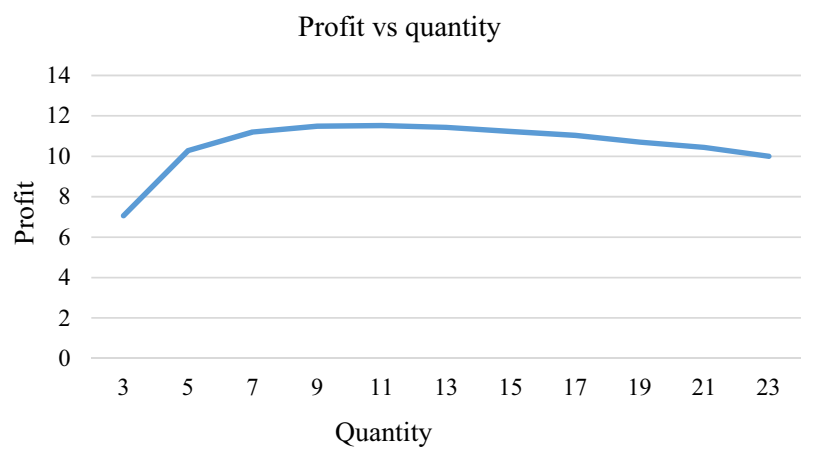

Fig. 5 Average profit versus quantity

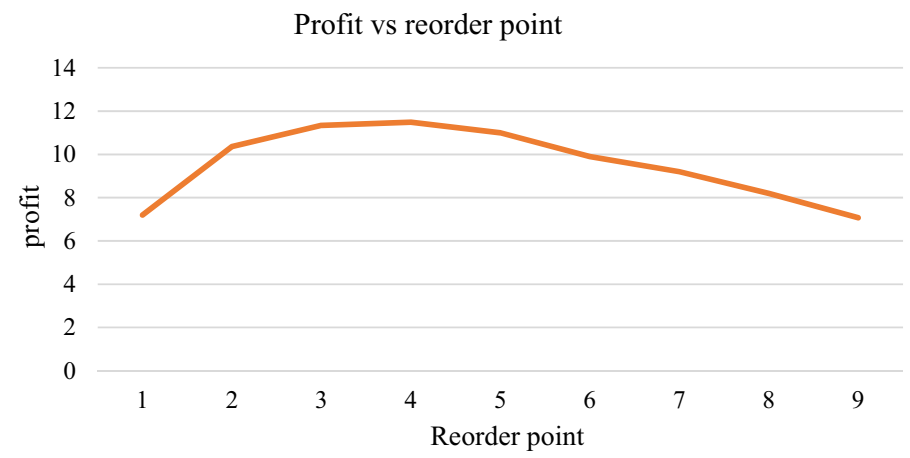

Fig. 6 Profit versus reorder point

\section{Sensitivity analysis}

In this study, we performed a sensitivity analysis to study the effects of the parameters presented in the model. In Table 4, we presented three different levels of experimental data set where level 1 constitutes the basic value of those parameters. In level 2 and level 3, the basic values of those parameters were increased by $+20 \%$ and $+40 \%$ respectively.

The optimal value of particular decision variables and the value of the objective function were generated using GA through MATLAB R2013a. The result of the objective function was calculated at different levels of the model parameters which are shown in Table 5. Case 1 is the basic model result and all the remaining cases show the function results at level 2 and 3 . Each of the cases represents each of the 15 parameters provided in Table 4 . To conduct this sensitivity analysis, a total of 31 cases were solved and each of these is outlined in Table 5.

Using this sensitivity analysis, we make the following observations.

Cases 2 and 3 clearly show that the reordering point and ordering quantity automatically decrease due to an increase in the holding cost. This suggests that if the holding cost is increased, then any product should be ordered at a lower amount. So too, the reordering point should be low so that the cost of keeping safety stock is minimized. Average profit is decreased ( $-16.84 \%$ and $-32.5 \%$ respectively) for a $20 \%$ and $40 \%$ increase in the holding cost.

Cases 4 and 5 show an increase in acceptable unit mark-up selling price factor $m_{1}$ from 20 to $40 \%$ increases the profit drastically from 30.77 to 55.3 . This is because by increasing $m_{1}$, it 
Table 4 Experimental data set for sensitivity analysis

\begin{tabular}{llll}
\hline Parameter & Basic (Level 1) & Level 2(+20\%) & Level 3 (+ 40\%) \\
\hline$H$ & 2 & 2.4 & 2.8 \\
$m_{1}$ & 3 & 3.6 & 4.2 \\
$m_{2}$ & 0.2 & 0.24 & 0.28 \\
$\varepsilon$ & 0.05 & 0.06 & 0.07 \\
$C$ & 5 & 6 & 7 \\
$P$ & 10 & 12 & 14 \\
$K$ & 10 & 12 & 14 \\
$\Pi$ & 25 & 30 & 35 \\
$\pi^{\prime}$ & 2.5 & 3 & 3.5 \\
$\lambda$ & 0.25 & 0.3 & 0.35 \\
$\mu$ & 2.5 & 3 & 3.5 \\
$\alpha$ & 1 & 1.2 & 1.4 \\
$\beta$ & 0.6 & 0.72 & 0.84 \\
$\theta$ & 0.025 & 0.03 & 0.035 \\
$\gamma$ & 5 & 6 & 7 \\
\hline
\end{tabular}

increases selling price directly and adds the benefit to the profit value. But the $\mathrm{m}_{1}$ value cannot be increased without proper investigation of market competitors. Increasing $\mathrm{m}_{1}$ decreases the quantity ordered and re-order quantity, as well as supplier reliability requirements. So, $\mathrm{m}_{1}$ is a more sensitive parameter compared to others.

Cases 6 and 7 include increasing the selling price mark-up factor $m_{2}$ which increases average profit, but not by a remarkable amount. It is not a much more sensitive parameter.

Increasing inspection cost increases the quantity ordered and decreases average profit. This is evident in cases 8 and 9. Increasing the inspection cost also increases the reliability requirement on the supplier.

In cases 10 and 11, we observe that increasing rejection costs by $20 \%$ decreases profit from 11.58 to 10.68 . Further increases by $40 \%$ decrease profit to 10.02 . Here, increasing rejection costs reduces profit and increases reliability requirements, the quantity ordered and the reordering point. This case illustrates the way increasing the rejection cost can eventually reduce profit. So, a more reliable supplier and ordering more than before in a single order can result in increasing rejection costs.

Cases 14 and 15 indicate the increase of lot size, as well as the reordering point with an increase in ordering cost. Therefore, lot sizes are ordered in large quantities when ordering costs are high. The average profit is not much affected by increased ordering costs.

Cases 16, 17, 18 and 19 reveal that increases in back ordering costs cause both the reordering point and ordering quantities to increase and eventually reduce profit. This suggests that more stocks should be ready in the warehouse to avoid any potential shortage whenever back ordering costs are increased. Average profit decreases as more safety stock is needed to be held as inventory. This is how the total profit per cycle decreases.

Cases 20 and 21 show that when the duration of an ON period of the supplier is high, suppliers are expected to be available for an extended period of time. Finally, decreased values of $r$ will cause the value of the order up to level $(q+r)$ to be lower. 
Table 5 Sensitivity analysis on different parameter level

\begin{tabular}{|c|c|c|c|c|c|c|}
\hline Case & Parameter & Level & $q$ & $r$ & $N$ & Profit \\
\hline 1 & Basic model & 1 & 9.903 & 3.823 & 0.636 & 11.521 \\
\hline 2 & $H$ & 2 & 9.9 & 3.44 & 0.668 & 9.58 \\
\hline 3 & $H$ & 3 & 9.457 & 3.256 & 0.691 & 7.77 \\
\hline 4 & $m_{1}$ & 2 & 5.44 & 3.82 & 0.57 & 30.77 \\
\hline 5 & $m_{1}$ & 3 & 4.16 & 3.72 & 0.55 & 55.3 \\
\hline 6 & $m_{2}$ & 2 & 9.22 & 3.69 & 0.59 & 12.18 \\
\hline 7 & $m_{2}$ & 3 & 8.27 & 3.63 & 0.56 & 12.99 \\
\hline 8 & $\varepsilon$ & 2 & 10.35 & 3.67 & 0.65 & 11.12 \\
\hline 9 & $\varepsilon$ & 3 & 10.84 & 3.69 & 0.66 & 10.72 \\
\hline 10 & $C$ & 2 & 10.54 & 3.69 & 0.707 & 10.68 \\
\hline 11 & $C$ & 3 & 12.54 & 3.98 & 0.77 & 10.04 \\
\hline 12 & $P$ & 2 & 14.84 & 3.72 & 0.77 & 4.8 \\
\hline 13 & $P$ & 3 & 16.73 & 3.8 & 0.9 & 1.02 \\
\hline 14 & $K$ & 2 & 10.097 & 3.897 & 0.645 & 11.11 \\
\hline 15 & $K$ & 3 & 12.02 & 3.615 & 0.655 & 10.82 \\
\hline 16 & $\Pi$ & 2 & 13.45 & 3.803 & 0.679 & 10.161 \\
\hline 17 & $\Pi$ & 3 & 14.822 & 4.25 & 0.696 & 9.025 \\
\hline 18 & $\pi^{\prime}$ & 2 & 10.683 & 3.692 & 0.647 & 11.382 \\
\hline 19 & $\pi^{\prime}$ & 3 & 10.864 & 3.706 & 0.648 & 11.23 \\
\hline 20 & $\lambda$ & 2 & 12.23 & 3.649 & 0.658 & 10.07 \\
\hline 21 & $\lambda$ & 3 & 14.78 & 3.63 & 0.662 & 8.88 \\
\hline 22 & $\mu$ & 2 & 7.046 & 3.172 & 0.599 & 14.73 \\
\hline 23 & $\mu$ & 3 & 5.881 & 2.79 & 0.577 & 17.55 \\
\hline 24 & $\alpha$ & 2 & 10.668 & 4.129 & 0.66 & 8.23 \\
\hline 25 & $\alpha$ & 3 & 14.634 & 4.079 & 0.661 & 6.03 \\
\hline 26 & $\beta$ & 2 & 8.761 & 3.47 & 0.632 & 14.298 \\
\hline 27 & $\beta$ & 3 & 7.91 & 3.36 & 0.6 & 16.7 \\
\hline 28 & $\theta$ & 2 & 10.12 & 3.69 & 0.63 & 11.42 \\
\hline 29 & $\theta$ & 3 & 9.9 & 3.68 & 0.628 & 11.33 \\
\hline 30 & $\gamma$ & 2 & 11.08 & 4.98 & 0.63 & 13.93 \\
\hline 31 & $\gamma$ & 3 & 13.91 & 5.32 & 0.66 & 16.31 \\
\hline
\end{tabular}

Cases 22 and 23 indicate that when an OFF period duration is low, meaning suppliers are not likely to be OFF for an extended time period, reorder points also should be small, because the possibility of finding them in an OFF state will be less.

Cases 28 and 29 indicate that when the chance of a supplier's delivery quantity becomes smaller than the actual quantity ordered, it should be beneficial to order less quantity.

Cases 30 and 31 are more crucial than others we found in the analysis. These stages indicate that an inflating demand rate causes fast increases in the quantity ordered and in reorder points, to meet the high demand. The average profit value reveals that the model is highly sensitive to a demand rate increase. In fact, it increased to 13.93 because of a $20 \%$ increase, and 16.31 because of a $40 \%$ increase. We can say, then, that demand rate is a very sensitive parameter in the model, so we should be careful while changing this parameter. 


\section{Managerial and practical implications}

In this study, the developed framework can be used to mimic the problems faced in real-world in three stage supply chain where disruption occurs due to capacity, demand, natural disasters or uncertain situations. Some practical implications of this study is below:

To ensure practicality, the supply chain managers and practitioners need to consider randomness in capacity to tackle the disruption risks associated with managing certain level of inventory. Since in our model, supply chain decisions are highly impacted by the random nature of capacity, it can lead the concerned personnel to optimize their inventory model.

- Reliability of supplier

Reliable suppliers can alleviate the risk of supply uncertainty in a large extent. Production responsible should always consider the reliability of the supply sources while making production schedule. As reliability decisions can impact the profit function, manufacturer should be aware of suboptimal and over optimal reliable suppliers to maximize profit.

- Structured inventory policy

Managers should always work with a structured and well defined inventory policy to excel in the competitive market. To reduce production cost and eventually maximize profit, it is of utmost importance to guide purchase decisions through some rigorous inventory policy so that production lines do not run dry and also warehouses are not overstocked with supplies. In this case, our model can guide them into managing the inventory system in an optimized way.

\section{Conclusions}

In this research, we considered an imperfect production environment where a model is formulated to ensure maximum profit. Here, profitability was a function of the order quantity, reorder point and reliability. In a manufacturing system, imperfect production can result in defective items. To improve product quality and thus reduce defective items, process reliability needs to be increased. On the other hand, increasing reliability causes increase in the operating cost and thus decreases profit. Therefore, to maximize profit, an optimum level of reliability needs to be ensured. As we developed our model considering reliability and uncertainty of the process, we can apply this model in imperfect production systems to have a better understanding of a realistic production inventory model.

In many small and medium scale manufacturing industries, inventory policies are absent to address the supply and demand uncertainty issues. Sometimes, communication gap and lack of information sharing between purchase and planning department results in an imbalanced production plan. To produce a single product, hundreds of different components are required. By not having a rigorous inventory policy, sometimes it is very common in apparel industry to not start the production due to delay in some trims even though having most of the components inhoused on time. This kind of scheduling problem can be avoided by addressing the reliability of the suppliers. Additionally, strikes, natural disasters, port congestion, heavy traffic can dirupt the chain in a large extent. For example, in most of the manufacturing industries, China is the biggest supplier of raw materials to the production facilities throughout the world. Every year, due to Chinese New Year (CNY) celebration, all the industries in China get closed for around 10-14 days. These types of supply disruption impact the manufacturing industries heavily if not prepared beforehand with proper inventory policies and contingency plan. 
Similarly, recent Coronavirus has taken the global manufacturing industries to a standstill situation due to production, supply and demand uncertainty. All these types of disruption and uncertainty issues need to be addressed in every manufacturing industry through some rigorous inventory policies to maximize the total supply chain gain. Through this model, we can address those random supplier's unavailability and disruption issues.

One important factor that has often been overlooked in most research done previously is that when needed, the supplier may or may not be able to deliver the amount desired. They have limited capacity. The demand, the time interval between successive availability and unavailability of both the supplier and retailer follows probability distributions. All these factors are considered in this study simultaneously.

In our study we assumed that the demand factor follows a Poisson process. Using concepts from the Renewal Reward Theorem, the objective function is developed which dictates an average cycle profit. By using a genetic algorithm, this function is maximized. Finally, a sensitivity analysis is done to analyse the significance of various factors used in the model and their interactions on decision variables and average cost. In our model we found that demand rate is a the most sensitive parameter and has the highest influence on the final profit function. Thus, it can be summarized that the methodology developed in this paper is a step towards better understanding the situation around us through joint consideration of disruption at both the retailer and the supplier, with consideration of their random capacity and reliability.

In this research, we considered reliability as deterministic in nature. In future studies, the profit function model may be updated considering reliability as a variable having probabilistic characteristics. Additionally, the probability of imperfect products and customer demands can be altered as probabilistic factors for further studies. In this research, it was assumed that the manufacturer had only one supplier. So, the work can be extended with a view to developing an inventory model for multiple suppliers. It has been assumed in this model that an order can only be given at the time when both the supplier and retailer are available. But the manufacturer can order at a time when the supplier is available, but the retailer is unavailable. This factor should be considered to make the model even more robust. In this model, four states CTMC were used to find transition state probability. But a semi-Markov chain can also be applied to get a better result. The model can be further extended to consider production disruption, lead time and shortage as fuzzy random variables. Again, the model developed an objective function which was minimized by using only one computational optimizing procedure, Genetic Algorithm. More algorithms can be used to check whether the model gives the same result every time.

\section{Appendix}

See Tables 6, 7 and 8. 
Table 6 Cycle profit, quantity, reorder point as a function of supplier reliability

Table 7 Cycle profit, supplier reliability, reorder point as a function of quantity

\begin{tabular}{lcll}
\hline Reliability (n) & Profit & Quantity (q) & Reorder point (r) \\
\hline 0.1 & -54.1 & 7.72 & 0.77 \\
0.2 & -11.23 & 7.47 & 2 \\
0.3 & 2.3 & 7.42 & 2.68 \\
0.4 & 8.1 & 7.73 & 3.11 \\
0.5 & 10.6 & 8.51 & 3.41 \\
0.6 & 11.46 & 9.73 & 3.7 \\
0.7 & 11.43 & 11.32 & 3.73 \\
0.8 & 10.8 & 12.95 & 3.88 \\
0.9 & 9.9 & 14.9 & 3.88 \\
1 & 8.8 & 16.3 & 4.01 \\
\hline
\end{tabular}

\begin{tabular}{llll}
\hline Quantity (q) & Profit & Reliability & Reorder point \\
\hline 3 & 7.06 & 0.57 & 3.8 \\
5 & 10.28 & 0.59 & 3.83 \\
7 & 11.2 & 0.61 & 3.8 \\
9 & 11.49 & 0.63 & 3.73 \\
11 & 11.52 & 0.649 & 3.65 \\
13 & 11.43 & 0.665 & 3.56 \\
15 & 11.23 & 0.68 & 3.47 \\
17 & 11.03 & 0.69 & 3.39 \\
19 & 10.7 & 0.71 & 3.31 \\
21 & 10.44 & 0.72 & 3.18 \\
23 & 10 & 0.73 & 3.17 \\
\hline
\end{tabular}

Table 8 Cycle profit, quantity, supplier reliability as a function reorder point

\begin{tabular}{lccl}
\hline Reorder point & Profit & Quantity & Reliability \\
\hline 1 & 7.2 & 10.82 & 0.588 \\
2 & 10.36 & 13.74 & 0.638 \\
3 & 11.34 & 10.24 & 0.625 \\
4 & 11.49 & 10.16 & 0.648 \\
5 & 11 & 9.56 & 0.661 \\
6 & 9.9 & 7.5 & 0.64 \\
7 & 9.2 & 9.5 & 0.704 \\
8 & 8.2 & 12.1 & 0.74 \\
9 & 7.07 & 10.8 & 0.748 \\
\hline
\end{tabular}

\section{References}

Bag, S., Chakraborty, D., \& Roy, A. R. (2009). A production inventory model with fuzzy random demand and with flexibility and reliability considerations. Computers \& Industrial Engineering, 56(1), 411-416. 
Cárdenas-Barrón, L. E., Shaikh, A. A., Tiwari, S., \& Treviño-Garza, G. (2018). An EOQ inventory model with nonlinear stock dependent holding cost, nonlinear stock dependent demand and trade credit. Computers \& Industrial Engineering, 139, 105557.

Dada, M., Petruzzi, N. C., \& Schwarz, L. B. (2007). A newsvendor's procurement problem when suppliers are unreliable. Manufacturing and Service Operations Management, 9(1), 9-32.

Dem, H., Singh, S. R., \& Parasher, L. (2019). Optimal strategy for an inventory model based on agile manufacturing under imperfect production process. International Journal of Mathematics in Operational Research, 14(1), 106-122.

Giri, B. C., \& Sarker, B. R. (2019). Coordinating a multi-echelon supply chain under production disruption and price-sensitive stochastic demand. Journal of Industrial and Management Optimization, 15(4), $1631-1651$.

Gupta, D. (1996). The $\{\mathrm{Q}, \mathrm{r})$ inventory system with an unreliable supplier. INFOR: Information Systems and Operational Research, 34(2), 59-76.

Heydari, J., \& Norouzinasab, Y. (2016). Coordination of pricing, ordering, and lead time decisions in a manufacturing supply chain. Journal of Industrial and Systems Engineering, 9(special issue on supply chain), 1-16.

Hishamuddin, H., Sarker, R. A., \& Essam, D. (2013). A recovery model for a two-echelon serial supply chain with consideration of transportation disruption. Computers \& Industrial Engineering, 64(2), 552-561.

Huang, H., He, Y., \& Li, D. (2018). Coordination of pricing, inventory, and production reliability decisions in deteriorating product supply chains. International Journal of Production Research, 56(18), 6201-6224.

Li, S., He, Y., \& Chen, L. (2017). Dynamic strategies for supply disruptions in production-inventory systems. International Journal of Production Economics, 194, 88-101.

Lücker, F., Seifert, R. W., \& Biçer, I. (2019). Roles of inventory and reserve capacity in mitigating supply chain disruption risk. International Journal of Production Research, 57(4), 1238-1249.

Mohebbi, E., \& Hao, D. (2006). When supplier's availability affects the replenishment lead time-An extension of the supply-interruption problem. European Journal of Operational Research, 175(2), 992-1008.

Mohebbi, E., \& Hao, D. (2008). An inventory model with non-resuming randomly interruptible lead time. International Journal of Production Economics, 114(2), 755-768.

Parlar, M. (1997). Continuous-review inventory problem with random supply interruptions. European Journal of Operational Research, 99(2), 366-385.

Parlar, M., \& Berkin, D. (1991). Future supply uncertainty in EOQ models. Naval Research Logistics (NRL), 38(1), 107-121.

Parlar, M., \& Perry, D. (1995). Analysis of a (Q, r, T) inventory policy with deterministic and random yields when future supply is uncertain. European Journal of Operational Research, 84(2), 431-443.

Paul, S. K., Asian, S., Goh, M., \& Torabi, S. A. (2019a). Managing sudden transportation disruptions in supply chains under delivery delay and quantity loss. Annals of Operations Research, 273(1-2), 783-814.

Paul, S. K., Azeem, A., Sarker, R., \& Essam, D. (2014a). Development of a production inventory model with uncertainty and reliability considerations. Optimization and Engineering, 15(3), 697-720.

Paul, S. K., Sarker, R., \& Essam, D. (2013). A production inventory model with disruption and reliability considerations. In Proceedings of international conference on computers and industrial engineering, Hong Kong.

Paul, S. K., Sarker, R., \& Essam, D. (2014b). Real time disruption management for a two-stage batch production-inventory system with reliability considerations. European Journal of Operational Research, 237(1), 113-128.

Paul, S. K., Sarker, R., \& Essam, D. (2014c). Managing real-time demand fluctuation under a supplier-retailer coordinated system. International Journal of Production Economics, 158, 231-243.

Paul, S. K., Sarker, R., \& Essam, D. (2015a). Managing disruption in an imperfect production-inventory system. Computers \& Industrial Engineering, 84, 101-112.

Paul, S. K., Sarker, R., \& Essam, D. (2015b). A disruption recovery plan in a three-stage production-inventory system. Computers \& Operations Research, 57, 60-72.

Paul, S. K., Sarker, R., Essam, D., \& Lee, P. W. (2019b). A mathematical modelling approach for managing sudden disturbances in a three-tier manufacturing supply chain. Annals of Operations Research, 280(1-2), 299-335. https://doi.org/10.1007/s10479-019-03251-w.

Qi, L. (2013). A continuous-review inventory model with random disruptions at the primary supplier. European Journal of Operational Research, 225(1), 59-74.

Rohaninejad, M., Sahraeian, R., \& Tavakkoli-Moghaddam, R. (2018). Multi-echelon supply chain design considering unreliable facilities with facility hardening possibility. Applied Mathematical Modelling, 62, 321-337.

Sana, S. S. (2010). A production-inventory model in an imperfect production process. European Journal of Operational Research, 200(2), 451-464. 
Sarkar, B. (2012). An inventory model with reliability in an imperfect production process. Applied Mathematics and Computation, 218(9), 4881-4891.

Schmitt, T. G., Kumar, S., Stecke, K. E., Glover, F. W., \& Ehlen, M. A. (2017). Mitigating disruptions in a multi-echelon supply chain using adaptive ordering. Omega, 68, 185-198.

Silbermayr, L., \& Minner, S. (2014). A multiple sourcing inventory model under disruption risk. International Journal of Production Economics, 149, 37-46.

Sting, F. J., \& Huchzermeier, A. (2012). Dual sourcing: Responsive hedging against correlated supply and demand uncertainty. Naval Research Logistics (NRL), 59(1), 69-89.

Torkul, O., Yılmaz, R., Selvi, I. H., \& Cesur, M. R. (2016). A real-time inventory model to manage variance of demand for decreasing inventory holding cost. Computers \& Industrial Engineering, 102, 435-439.

Yan, R., Kou, D., \& Lu, B. (2019). Optimal order policies for dual-sourcing supply chains under random supply disruption. Sustainability, 11(3), 698.

Yao, M., \& Minner, S. (2017). Review of multi-supplier inventory models in supply chain management: An update. Available at SSRN 2995134 (2017).

Publisher's Note Springer Nature remains neutral with regard to jurisdictional claims in published maps and institutional affiliations.

\section{Affiliations}

\section{Md. Tariqul Islam ${ }^{1} \cdot$ Abdullahil Azeem ${ }^{1} \cdot$ Masum Jabir $^{1} \cdot$ Ananna Paul $^{2}$.} Sanjoy Kumar Paul ${ }^{3}$ (D)

$\varangle \quad$ Sanjoy Kumar Paul

Sanjoy.Paul@uts.edu.au

Md. Tariqul Islam

tariq.redwan@gmail.com

Abdullahil Azeem

azeem@ipe.buet.ac.bd

Masum Jabir

jabirbuetipe@yahoo.com

Ananna Paul

ananna.du@gmail.com

1 Department of Industrial and Production Engineering, Bangladesh University of Engineering and Technology, Dhaka, Bangladesh

2 Faculty of Engineering and Information Technology, University of Technology Sydney, Sydney, Australia

3 UTS Business School, University of Technology Sydney, Sydney, Australia 